\title{
Isolated Addison's disease is unlikely to be caused by mutations in MC2R, MRAP or STAR, three genes responsible for familial glucocorticoid deficiency
}

\author{
R P Dias, L F Chan, L A Metherell, S H S Pearce ${ }^{1}$ and A J L Clark \\ Barts and the London School of Medicine and Dentistry, Centre for Endocrinology, John Vane Science Centre, Queen Mary University of London, \\ Charterhouse Square, London EC1M 6BQ, UK and ${ }^{1}$ Institute of Human Genetics, Centre for Life, Newcastle University, Central Parkway, \\ Newcastle upon Tyne NE1 3BZ, UK \\ (Correspondence should be addressed to A J L Clark; Email: a.j.clark@qmul.ac.uk)
}

\begin{abstract}
Background: Familial glucocorticoid deficiency (FGD) is a rare autosomal recessive disease caused by ACTH resistance and leads to isolated glucocorticoid deficiency. Although FGD patients typically have normal mineralocorticoid secretion, subtle alterations in the renin-angiotensin-aldosterone axis have been reported in a subset of patients at presentation. Anecdotally, some patients with FGD have been initially diagnosed as having Addison's disease (AD), with implications for treatment and genetic counselling. Currently, mutations in three genes: the ACTH receptor $(M C 2 R)$; the melanocortin 2 receptor accessory protein (MRAP); and the steroidogenic acute regulatory protein (STAR) are known to give rise to FGD types 1-3. We investigated a cohort of autoantibody-negative AD patients for mutations in these genes. Methods: Forty patients with known AD without evidence of autoimmune disease were screened for mutations in $M C 2 R, M R A P$ and STAR. In addition, patients were genotyped for the MC2R promoter polymorphism previously associated with reduced responsiveness to ACTH.

Results: No mutations in MC2R, MRAP or STAR were identified in any patient. The frequencies of the $M C 2 R$ promoter polymorphism were similar to those reported in healthy controls.

Conclusions: FGD does not appear to be underdiagnosed in the AD population. However, in $\sim 50 \%$ of patients with FGD, no genetic cause has yet been identified and it is possible that the other, as yet unidentified, genes giving rise to FGD may be implicated in AD.
\end{abstract}

European Journal of Endocrinology 162 357-359

\section{Introduction}

Primary adrenal failure is relatively rare with a prevalence of approximately five cases per 100000 in Northern Europe $(1,2)$. The initial cases described by Addison in 1855 involved tuberculosis, adrenal malignancy and idiopathic adrenal fibrosis, which is now thought to be the first report of autoimmune adrenal disease (3). Currently, autoimmune Addison's disease $(\mathrm{AAD})$ accounts for the majority of cases of primary adrenal failure in western countries (up to 94\%) (1). AAD can occur either in conjunction with other autoimmune conditions (autoimmune polyendocrine syndromes), or in isolation. Isolated AAD with no other autoimmune clinical manifestations occurs in about $40 \%$ of cases, but positive autoantibodies have been shown to be present in up to $80 \%$ of these (4).

Primary adrenal insufficiency (or antibody-negative AD) covers a broad spectrum of pathologies including malignant, infectious and genetic causes. Genetic causes range from autosomal or $\mathrm{X}$-linked recessive conditions such as familial ACTH resistance syndromes (familial glucocorticoid deficiency (FGD), Triple A), congenital adrenal hyperplasia and adrenoleukodystrophy to mitochondrial disorders such as KearnsSayres syndrome.

FGD (OMIM 202200) is an autosomal recessive condition characterised by ACTH resistance leading to isolated glucocorticoid deficiency with normal mineralocorticoid secretion. The syndrome was first described by Shepard et al. in 1959 in two siblings who had initially been diagnosed with AD (5). However, although patients with FGD have normal renin and aldosterone levels, subtle abnormalities of the reninangiotensin axis are sometimes seen in this condition at diagnosis, most notably with nonsense mutations of the ACTH receptor $(M C 2 R)(6,7)$. In contrast, the recently described $M C 2 R$ knockout mouse model demonstrates classical adrenal failure with both glucocorticoid and mineralocorticoid deficiency (8).

The first inactivating mutation of the $M C 2 R$ (also known as the melanocortin type 2 receptor) in a patient with FGD was reported in 1993 (9), and subsequently more than 30 mutations in the $M C 2 R$ have been non-commercial use, distribution, and reproduction in any medium, provided the original work is properly cited. 
found (10). In 2004, a polymorphism in the MC2R promoter at position 2 was described as having decreased response to ACTH both in vitro and in normal human subjects following i.v. ACTH infusion (11). More recently, mutations in a novel gene, the melanocortin 2 receptor accessory protein (MRAP), which is involved in trafficking $M C 2 R$ to the plasma membrane, have been described in FGD (12). In 2009, Metherell et al. reported that a proportion of patients with FGD (5-10\%) have mutations in STAR (13). STAR mutations usually give rise to a severe form of adrenal insufficiency known as lipoid congenital adrenal hyperplasia (LCAH; OMIM 201701), leading to both mineralocorticoid and glucocorticoid deficiency. Mutations in these three genes lead to FGD types 1, 2 and 3 respectively and account for just over $50 \%$ of all known clinical cases of FGD. Furthermore, there are reports of patients initially diagnosed with AD subsequently having their diagnosis refined to FGD, allowing them to omit their mineralocorticoid replacement therapy (5). Of note, two families found to have STAR mutations leading to adrenal failure were initially diagnosed with non-AAD. Having noted that there appear to be certain mutations in MC2R and STAR causing adrenal failure with both mineralocorticoid and glucocorticoid abnormalities, we investigated here the possibility that a subset of patients with isolated $\mathrm{AD}$ without evidence of autoimmune disease may have mutations in MC2R, MRAP or STAR. In addition, we screened the AD cohort for possible increased frequency of the $M C 2 R$ promoter polymorphism associated with reduced responsiveness to ACTH.

\section{Subjects and methods}

\section{Patients}

Forty patients (17 males and 23 females) with isolated AD were identified from a previously described cohort of patients studied in the north-east of England (14). The mean age of diagnosis was 36.5 years (range 8-79 years). All patients demonstrated a peak cortisol response of $<550 \mathrm{nmol} / \mathrm{l}$ following a short synacthen test $(250 \mu \mathrm{g}$ synthetic ACTH administered i.m). All patients had a diagnosis of primary adrenal failure (secondary adrenal failure, infiltrative and infective causes were excluded). All patients with evidence of autoimmune disease or polyendocrinopathy (positive adrenal autoantibody screen by immunofluorescence or other organ system affected, e.g. thyroid dysfunction, vitiligo, type 1 diabetes mellitus and pernicious anaemia) were excluded. Patients with any family history of autoimmune disease were excluded. No patient had formal investigation of the renin-angiotensin axis, although none were known to have maintained normal mineralocorticoid secretion. There was one familial case of $\mathrm{AD}$ in the cohort (mother diagnosed at the age of 28 years and her son diagnosed at the age of 8 ).

\section{DNA extraction}

Genomic DNA was extracted from whole blood using the Nucleon BACC DNA extraction kit according to the manufacturer's instructions (GE Healthcare, Buckinghamshire, UK).

\section{Sequencing}

$M C 2 R$ has a single-coding exon. It has previously been reported that the majority of the mutations in MRAP in FGD patients are in exon 3. Exon 5 of $S T A R$ is where all mutations in non-classical LCAH and/or FGD have been described $(6,13,15)$, whereas mutations found in other exons in this gene cause the classical LCAH phenotype.

PCR was carried out using published primers directed to intronic sequences to cover the coding exon of $M C 2 R$, exon 3 of MRAP and exons 5 and 6 of STAR in the entire $\mathrm{AD}$ cohort $(12,13)$. Cycling conditions were $95^{\circ} \mathrm{C}$ for $5 \mathrm{~min}(1 \mathrm{cycle}) ; 95^{\circ} \mathrm{C}$ for $30 \mathrm{~s}, 55^{\circ} \mathrm{C}$ for $30 \mathrm{~s}$ and $72{ }^{\circ} \mathrm{C}$ for $30 \mathrm{~s}$ ( 30 cycles); and $72{ }^{\circ} \mathrm{C}$ for $5 \mathrm{~min}$. PCR products were visualized on $1 \%$ agarose gel, and PCR fragments were sequenced using the ABI Prism Big Dye Sequencing kit and an ABI 3700 automated DNA sequencer (Applied Biosystems, Foster City, CA, USA) in accordance with the manufacturer's instructions.

\section{Genotyping}

PCR was carried using previously published primers around the $-2 M C 2 R$ promoter polymorphism (11). PCR products were digested with Sac1 giving three possible genotypes (CTC/CTC homozygote, CTC/CCC heterozygote and $\mathrm{CCC} / \mathrm{CCC}$ homozygote), when run on a $2 \%$ agarose gel as previously reported. To confirm the accuracy of restriction enzyme digestion, conventional sequencing of three apparent homozygotes for both alleles and three heterozygotes was carried out as above.

\section{Results}

No mutations in MC2R, MRAP or STAR were identified in any patient. There were no single nucleotide polymorphisms (SNPs) identified in the $M C 2 R$ coding exon, but a number of individuals had a previously reported intronic SNP (rs2254251) downstream of exon 3 of MRAP.

For the promoter polymorphism in $M C 2 R$, the $\mathrm{C}$ allele frequency in our patient population was $0.112(9 / 80)$, which is comparable with the HapMap CEPH SNP database $\mathrm{C}$ allele frequency of 0.117 . In the $\mathrm{AD}$ cohort studied, frequencies of $M C 2 R$ promoter polymorphism were not significantly different to previously reported frequencies in normal controls using $\chi^{2}$ test with 2 d.f.: CTC/CTC 71.0\% (80.2\%); CTC/CCC 26.4\% (19.0\%) and 
$\mathrm{CCC} / \mathrm{CCC} 2.6 \%(0.8 \%)$; figures given in parentheses describe reported frequencies in healthy controls (11). The population studied was in Hardy-Weinberg equilibrium.

\section{Discussion}

$\mathrm{AD}$ is a common cause of adrenal failure in adults. In our cohort of FGD patients and other reported patients with non-classical LCAH, there are several reports of family members diagnosed initially with Addison's disease or with late onset of symptoms of glucocorticoid deficiency who have subsequently been found to have mutations in MC2R or STAR with alterations in their renin-angiotensin-aldosterone axis. However, our results indicate that FGD is not being underdiagnosed within the wider AD population in the UK. Furthermore, there does not appear to be any significant increase in the $M C 2 R$ promoter polymorphism consistent with reduced responsiveness to ACTH, consistent with other Caucasian populations previously reported $(11,16,17)$, although we accept that a detailed analysis of a local control population would be desirable. However, it may be that in other regions, mutation screening for FGD is not considered perhaps because of an atypical biochemical profile or resource considerations, and consequently such patients are being diagnosed as having antibody negative AD. Nevertheless, mutations in these genes account for only just over $50 \%$ of cases of FGD. It is known that there are several further loci involved in FGD and there is phenotypic variability in patients with FGD of unknown cause (18). It is possible that as yet unidentified gene(s) for FGD could account for familial cases of non-AAD.

\section{Declaration of interest}

There is no conflict of interest that could be perceived as prejudicing the impartiality of the research reported.

\section{Funding}

R P Dias is a Clinical Research Fellow funded by the Medical Research Council.

\section{References}

1 Kong MF \& Jeffcoate W. Eighty-six cases of Addison's disease. Clinical Endocrinology $1994 \mathbf{4 1}$ 757-761.

2 Nerup J. Addison's disease - clinical studies. A report of 108 cases. Acta Endocrinologica 197476 127-141.

3 Addison T, Ed. On the Constitutional and Local Effects of Disease of the Suprarenal Capsules. In: A Collection of the Published Writings of the late Thomas Addison MD. London: New Syndenham Society, 1855.

4 Betterle C, Dal Pra C, Mantero F \& Zanchetta R. Autoimmune adrenal insufficiency and autoimmune polyendocrine syndromes: autoantibodies, autoantigens, and their applicability in diagnosis and disease prediction. Endocrine Reviews 200223 327-364.
5 Shepard TH, Landing BH \& Mason DG. Familial Addison's disease; case reports of two sisters with corticoid deficiency unassociated with hypoaldosteronism. A.M.A. Journal of Diseases of Children $195997154-162$.

6 Chan LF, Metherell LA, Krude H, Ball C, O'Riordan SM, Costigan C, Lynch SA, Savage MO, Cavarzere P \& Clark AJ. Homozygous nonsense and frameshift mutations of the ACTH receptor in children with familial glucocorticoid deficiency are not associated with long-term mineralocorticoid deficiency. Clinical Endocrinology 2009 71 171-175.

7 Lin L, Hindmarsh PC, Metherell LA, Alzyoud M, Al-Ali M, Brain CE, Clark AJ, Dattani MT \& Achermann JC. Severe loss-of-function mutations in the adrenocorticotropin receptor (ACTHR, MC2R) can be found in patients diagnosed with salt-losing adrenal hypoplasia. Clinical Endocrinology 200766 205-210.

8 Chida D, Nakagawa S, Nagai S, Sagara H, Katsumata H, Imaki T, Suzuki H, Mitani F, Ogishima T, Shimizu C, Kotaki H, Kakuta S, Sudo K, Koike T, Kubo M \& Iwakura Y. Melanocortin 2 receptor is required for adrenal gland development, steroidogenesis, and neonatal gluconeogenesis. PNAS $2007 \mathbf{1 0 4} 18205-18210$.

9 Clark AJ, McLoughlin L \& Grossman A. Familial glucocorticoid deficiency associated with point mutation in the adrenocorticotropin receptor. Lancet $1993 \mathbf{3 4 1} 461-462$.

10 Clark AJ, Metherell LA, Cheetham ME \& Huebner A. Inherited ACTH insensitivity illuminates the mechanisms of ACTH action. Trends in Endocrinology and Metabolism 200516 451-457.

11 Slawik M, Reisch N, Zwermann O, Maser-Gluth C, Stahl M, Klink A, Reincke M \& Beuschlein F. Characterization of an adrenocorticotropin (ACTH) receptor promoter polymorphism leading to decreased adrenal responsiveness to ACTH. Journal of Clinical Endocrinology and Metabolism 200489 3131-3137.

12 Metherell LA, Chapple JP, Cooray S, David A, Becker C, Ruschendorf F, Naville D, Begeot M, Khoo B, Nurnberg P, Huebner A, Cheetham ME \& Clark AJ. Mutations in MRAP, encoding a new interacting partner of the ACTH receptor, cause familial glucocorticoid deficiency type 2. Nature Genetics 200537 166-170.

13 Metherell LA, Naville D, Halaby G, Begeot M, Huebner A, Nürnberg G, Nürnberg P, Green J, Tomlinson JW, Krone NP, Lin L, Racine M, Berney DM, Achermann JC, Arlt W \& Clark AJL. Non-classic lipoid congenital adrenal hyperplasia masquerading as familial glucocorticoid deficiency. Journal of Clinical Endocrinology and Metabolism 200994 3865-3871.

14 Vaidya B, Imrie H, Geatch DR, Perros P, Ball SG, Baylis PH, Carr D, Hurel SJ, James RA, Kelly WF, Kemp EH, Young ET, Weetman AP, Kendall-Taylor P \& Pearce SH. Association analysis of the cytotoxic T lymphocyte antigen-4 (CTLA-4) and autoimmune regulator-1 (AIRE-1) genes in sporadic autoimmune Addison's disease. Journal of Clinical Endocrinology and Metabolism 200085 688-691.

15 Baker BY, Lin L, Kim CJ, Raza J, Smith CP, Miller WL \& Achermann JC. Nonclassic congenital lipoid adrenal hyperplasia: a new disorder of the steroidogenic acute regulatory protein with very late presentation and normal male genitalia. Journal of Clinical Endocrinology and Metabolism 200691 4781-4785.

16 Lappalainen S, Utriainen P, Kuulasmaa T, Voutilainen R \& Jaaskelainen J. ACTH receptor promoter polymorphism associates with severity of premature adrenarche and modulates hypothalamo-pituitary-adrenal axis in children. Pediatric Research 2008 63 410-414.

17 Proudnikov D, Hamon S, Ott J \& Kreek MJ. Association of polymorphisms in the melanocortin receptor type 2 (MC2R, ACTH receptor) gene with heroin addiction. Neuroscience Letters 2008 $435234-239$.

18 O'Riordan SM, Lynch SA, Hindmarsh PC, Chan LF, Clark AJ \& Costigan C. A novel variant of familial glucocorticoid deficiency prevalent among the Irish Traveler population. Journal of Clinical Endocrinology and Metabolism 200893 2896-2899.

Received 15 October 2009

Accepted 19 October 2009 